\title{
Prunus Türlerine Ait Bazı Meyve Klon Anaçlarının (Şeftali, Erik ve Kiraz) Odun Çelikleri ile Köklendirilmesi
}

\author{
Selma BOYACI ${ }^{1} \quad$ Ruziye IZZMIR ${ }^{1} \quad$ Bektaş KIZIL $^{1}$ \\ ${ }^{1}$ Ahievran Üniversitesi, Ziraat Fakültesi, Bahçe Bitkileri Bölümü \\ $\triangle$ : selma.boyaci@ahievran.edu.tr
}

Geliş (Received): 26.12.2016

Kabul (Accepted): 15.03.2017

\begin{abstract}
ÖZET :Bu araştırmada Prunus türüne ait şeftali (GF-677, Garnem), erik (Marianna GF 8-1, St. Julien) ve kiraz (SL64) meyve klon anaçlarının odun çeliklerinin köklendirilmesi üzerine IBA'nın 0, 1000, 2000 ve 4000 ppm dozlarının etkisi incelenmiştir. Çalışmada uygulama yapılan çeliklerde; canlı çelik oranı (\%), kallus oluşum oranı (\%), köklenme oranı (\%), ortalama kök sayısı (adet) ve ortalama kök uzunluğu (mm) gibi özellikler incelenmiştir. Çalışma, 15 Aralık 2015-15 Mart 2016 tarihlerinde Ahi Evran Üniversitesi Ziraat Fakültesi Bahçe Bitkileri Bölümü uygulama serasında 4 tekerrürlü olarak yürütülmüştür. Araştırma sonuçlarına göre; IBA'nın tüm dozları incelenen özellikler yönünden kontrol uygulamasına göre daha iyi sonuçlar vermiştir. En yüksek köklenme oranı \% 38 ile 2000 ppm IBA uygulamasından, en düşük köklenme ise \% 19 ile tanık uygulamasından elde edilmiştir. Kullandığımız anaçların odun çeliklerinde incelenen özellikler için en uygun IBA dozu 2000 ppm olarak belirlenmiştir.
\end{abstract}

Anahtar Kelimeler: çoğaltma, çelik, meyve yetiştiriciliği

Rooting of Some Fruit Clone Rootstocks of Prunus Species (Peach, Plum and Cherry) with Harwood Cuttings

ABSTRACT : In this study, the effect of 0, 1000, 2000 and 4000 ppm doses of IBA on the rooting of hardwood cuttings of fruit clone rootstocks of Prunus species including peach (GF-677, Garnem), plum (Marianna GF 8-1, St. Julien) and cherry (SL-64) were investigated. The characteristics, such as live cutting ratio (\%), callus formation rate $(\%)$, rooting ratio $(\%)$, the mean number of roots (piece) and mean root length $(\mathrm{mm})$ of treated hardwood cuttings in were determined. The study was conducted with four-replication in the application greenhouse of Ahi Evran University, Faculty of Agriculture, Department of Horticulture, from December $15^{\text {th }}$ of 2015 to March $15^{\text {th }}$ of 2016. The study results indicated that all doses of IBA sustained better results in terms of the investigated characteristics comparing to the control application. The highest rooting ratio of $38 \%$ was obtained from 2000 ppm IBA application, while the lowest rooting ratio of $19 \%$ was obtained from the control application. The most appropriate dose of IBA for hardwood cuttings of the rootstocks was determined as $2000 \mathrm{ppm}$.

Keywords: propagation, cutting, fruit growing

\section{GİRIȘ}

Genel olarak meyve ağaçları generatif (eşeyli) ve vegetatif (eşeysiz) olmak üzere 2 şekilde çoğaltılmaktadır. Meyve ağaçlarında; tohumla çoğaltmada bir örnek materyal elde etmek mümkün olmadığı için zorunlu haller dışında pek tercih edilmemektedir (Ağaoğlu ve ark., 2001). Bitkilerin değişik yaşlarda gövde ve dal parçaları, büyüme uçlarındaki meristematik dokuları, kökleri, yaprakları ya da özelleşmiş veya değişikliğe uğramış gövde ve kök parçaları kullanılarak yapılan çoğaltmaya vegetatif (eşeysiz) çoğaltma denir. Vegetatif çoğaltma da bir örnek ismine doğru standart anaç eldesi mümkün olduğundan meyvecilikte en çok tercih edilen yöntemdir. Vegetatif çoğaltma yöntemlerinden biriside çelikle çoğaltmadır. Çelikle çoğaltma bitkilerin köksüz olan herhangi bir vegetatif parçasının uygun koşullarda köklendirilmesine verilen addır. $\mathrm{Bu}$ şekilde oluşan yeni bitki ana bitkinin tüm özelliklerini taşımaktadır. Çelikle çoğaltma eşeysiz çoğaltma yöntemlerinin en maliyetsiz ve basit yöntemlerinden birisidir. Çünkü çelikle çoğaltma oldukça kolay, ucuz ve çabuk olan bir yöntemdir (Barut, 2008). Çelikle çoğaltma işlemi; köklenmesi kolay olan türlerde rahatlıkla uygulanabilirken, köklenmesi zor olan türlerde bir takım uygulamaları (büyümeyi düzenleyici maddeler, yaralama vs.) zorunlu kılmıştır.
Klon anaçların vegetatif olarak üretilebilme imkanları büyük önem arz etmektedir. Bir anacın anaçlık vasfi ne kadar iyi olursa olsun vegetatif olarak çoğaltılmasının mümkün olmaması durumunda o anacın üretimde kullanmak söz konusu olmayacaktır. $\mathrm{Bu}$ nedenle anaçların özellikle vegetatif olarak çoğaltılabilme olanaklarının araştırılması gerekmektedir (Edizer ve Demirel, 2012). Bu bağlamda Prunus türüne ait şeftali (GF-677, Garnem), erik (Marianna GF 8-1, St. Julien) ve kiraz (SL-64) gibi meyve türlerinde çelikle köklendirilme üzerine yapılmış çalışmalar mevcuttur (Reighard ve ark., 1990; Özkan ve Madakbaş, 1995; Polat ve ark., 1997; Kankaya ve Özyiğit, 1998; Ahmed ve ark., 2003; Edizer ve Demirel, 2012; Ilgın ve Bulat, 2014).

$\mathrm{Bu}$ araştırmada Prunus türüne ait şeftali (GF-677, Garnem), erik (Marianna GF 8-1, St. Julien) ve kiraz (SL64) meyve klon anaçlarının odun çeliklerinin köklendirilmesi üzerine IBA'nın 0, 1000, 2000 ve 4000 ppm dozlarının etkisi incelenmiştir. Çalışmada uygulama yapılan çeliklerde canlı çelik oranı (\%), kallus oluşum oranı (\%), köklenme oranı (\%), ortalama kök sayısı (adet) ve ortalama kök uzunluğu $(\mathrm{mm})$ gibi özellikler incelenmiştir.

\section{MATERYAL ve METOT}

Bu çalışma 15 Aralık 2015 - 15 Mart 2016 tarihlerinde 3 ay süre ile Ahi Evran Üniversitesi Bahçe Bitkileri 
Bölümüne ait uygulama serasında yürütülmüştür. Çalışmada Dimes Kazova Vasfi DİREN Tarım İşletmesine ait meyve klon anaç damızlığından temin edilen şeftali (GF-677, Garnem), erik (Marianna GF 8-1, St. Julien) ve kiraz (SL-64) klon anaçlarından elde edilen odun çelikleri kullanılmıştır. Alınan çelikler $30 \mathrm{~cm}$ boyunda ve aynı kalınlıkta olacak şekilde hazırlanarak, köklenmeyi teşvik etmek için bazal kısımları bıçakla çizilerek 4 farklı dozda 0, 1000, 2000, 4000 ppm IBA (İndol Bütirik Asit) uygulaması yapılmıştır. IBA uygulaması, farklı dozlarda hazırlanan hormona çeliklerin 5 saniye süre ile batırılması şeklinde yapılmıştır. Hormon uygulaması yapılan çelikler köklendirme amacıyla sera ortamında içinde perlit bulunan ve alttan 1 sitmalı $\left(22-26^{\circ} \mathrm{C}\right)$ bençlere çeliklerin 1/3'lik kısmı dışarıda kalacak şekilde dikilmişlerdir (Kaşka ve Yılmaz, 1974). Deneme 4 tekerrürlü ve her tekerrürde 10 çelik olacak şekilde yürütülmüş ve çelikler 3 ay süreyle köklendirme ortamında tutulduktan sonra aşağıda belirtilen özellikler incelenmiştir.

Kallus oluşum oranı (\%): Köklendirme işlemi sonrası kallus oluşturan çelikler sayılarak \% olarak ifade edilmiştir.

Köklenme oranı (\%):Köklendirme ișlemi sonrası kök oluşturan çelikler sayılarak \% olarak ifade edilmiştir.

Canlı çelik oranı (\%): Köklendirme işlemi sonrası büyümesini devam ettiren, kallus oluşturan ve köklenen çelikler sayılarak \% olarak ifade edilmiştir.

Ortalama kök sayısı (adet): Köklendirme işlemi sonrası kök oluşturmuş tüm çeliklerdeki kökler sayılarak sonuçların ortalama değerleri hesaplanmıştır.

Ortalama kök uzunluğu (mm): Köklendirme işlemi sonrası kök oluşturmuş tüm çeliklerde kök uzunlukları ölçülerek sonuçların ortalama değerleri hesaplanmıştır.

$\mathrm{Bu}$ çalışmada kallus oluşum oranı (\%), köklenme oranı (\%), canlı çelik oranı (\%), ortalama kök sayısı (adet) ve ortalama kök uzunluğu (mm) gibi değişkenleri açısından uygulamalar arası farklılık ile çeşit-uygulama interaksiyonu SPSS 22.0 istatistiksel paket programı ile analiz edilmiştir. Bu amaçla faktöriyel düzende tesadüf parselleri deneme deseni dört tekrarlamalı olarak kullanılmıştır. Analizlerde ortalamalar arası farklılıkların istatistiksel açıdan önemli olduğu durumlarda gruplar arası farklılık Duncan çoklu karşılaştırma testi ile belirlenmiştir.

\section{BULGULAR ve TARTIŞMA \\ Kallus Olușum Oranı}

GF-677, Garnem, Marianna GF 8-1, St. Julien ve SL-64 klon anaçlarına uygulanan farklı IBA dozlarının kallus oluşum oranına olan etkileri Çizelge 3.1 ve Şekil 3.1'de verilmiştir. Genel olarak anaçlara farklı oranda uygulanan IBA dozları kallus oluşum oranını tanığa göre artırmıştır. Uygulamalar arasındaki bu farklılık istatistiksel olarak $(\mathrm{p}<0.01)$ düzeyinde çok önemli bulunmuştur. Çeliklerde tanık uygulamasından \%24 kallus oluşum oranı görülmesine karşın, IBA dozlarından 2000 ppm uygulamasından \%45 kallus oluşumu gerçekleşmiştir. Kallus oluşum oranı anaçlara göre istatistiki açıdan $(\mathrm{p}<0.01)$ farklılık göstererek, en yüksek kallus oluşum oranları GF-677 ve St.Julien anaçlarından $\% 43.1$, en düşük ise SL-64 anacından \%26.9 olarak belirlenmiştir. Uygulamalar x Anaç interaksiyonundaki farklılık istatistiksel olarak ( $p>0.05)$ düzeyinde önemsiz bulunmuştur. Farklı IBA dozu $\mathrm{x}$ anaç interaksiyonu bakımından en yüksek değer \%52.5 ile IBA'nın 2000 ppm dozu uygulanan GF-677 ve Marianna anaçlarında, en düşük değer ise \%12.5 ile Garnem anacının tanık uygulamasından elde edilmiştir. Şen ve Balta (1990) şeftali odun çeliklerine IBA'nın 1000 ppm ve 2000 ppm dozlarını uygulayarak yürüttükleri çalışmalarında en yüksek kallus oluşum oranına \%60.58 ile 2000 ppm IBA dozundan elde etmişlerdir. Edizer ve Demirel (2012) Marianna GF 8-1, St. Julien, Garnem, SL-64 klon anaçlarında yeşil çeliklere IBA'nın 0, 2000, 3000, 4000 ppm dozları uygulayarak yürüttükleri çalışmalarında en yüksek kallus oluşum oranını \%90 ile 3000 ppm IBA dozundan elde ettiklerini bildirmişlerdir. Çalışmamız ile uyumlu görülen bu literatürlerden elde ettiğimiz sonuçlar arasındaki farklılıklar; iklim ve doz farkı olarak açıklanabilir.

Çizelge 3.1. Farklı dozda IBA ve anaçların kallus oluşum oranına etkisi (\%)

\begin{tabular}{|c|c|c|c|c|c|}
\hline \multirow{2}{*}{ Anaç } & \multicolumn{4}{|c|}{ Uygulama } & \multirow{2}{*}{$\begin{array}{c}\text { Satır } \\
\text { Ortalamas1 }\end{array}$} \\
\hline & Tanık & $1000 \mathrm{ppm}$ & 2000ppm & 4000ppm & \\
\hline Gf-677 & 30.0 & 50.0 & 52.5 & 40.0 & $43.1 \mathrm{a}$ \\
\hline Garnem & 12.5 & 35.0 & 37.5 & 32.5 & $29.4 b$ \\
\hline St-Julien & 35.0 & 47.5 & 47.5 & 42.5 & $43.1 \mathrm{a}$ \\
\hline S1-64 & 15.0 & 32.5 & 35.0 & 25.0 & $26.9 b$ \\
\hline Marianna & 27.5 & 50.0 & 52.5 & 37.5 & $41.9 \mathrm{a}$ \\
\hline Sütun Ortalaması & $24.0 \mathrm{c}$ & $43.0 \mathrm{a}$ & $45.0 \mathrm{a}$ & $35.5 b$ & \\
\hline
\end{tabular}

Anaç(**) Uygulama(**) UygulamaxAnaç (ÖD) ÖD: Önemli değil

Farklı harfle gösterilen ortalamalar arasındaki fark (**) \%1 ve (*) \%5 düzeyinde önemlidir 


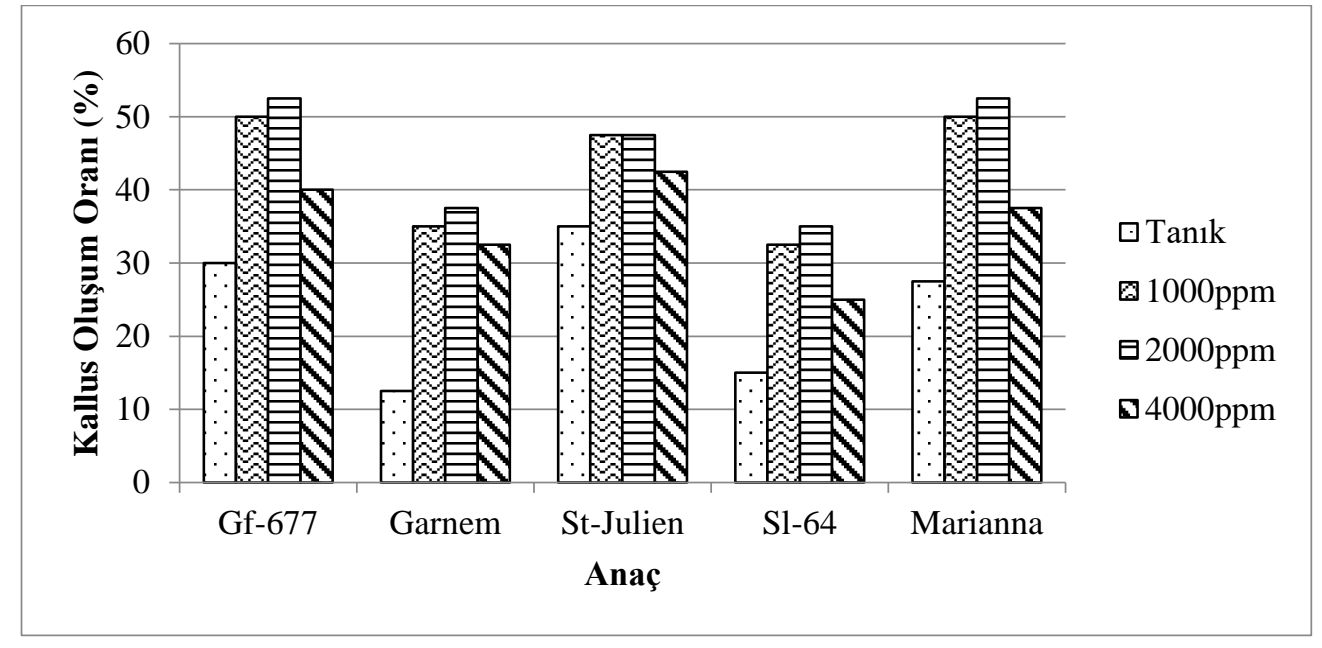

Şekil 3.1. Bazı Prunus türüne ait odun çeliklerine farklı IBA dozlarının kallus oluşum oranı üzerine etkisi

\section{Köklenme Oranı}

GF-677, Garnem, Marianna GF 8-1, St. Julien ve SL-64 klon anaçlarına uygulanan farklı IBA dozlarının köklenme oranına olan etkileri Çizelge 3.2 ve Şekil 3.2 'de verilmiştir. Genel olarak IBA dozları tanık uygulamasına göre daha yüksek bir köklenme oranı göstermiştir. Uygulamalar arasındaki bu farklılık istatistiksel olarak $(\mathrm{p}<0.01)$ düzeyinde çok önemli bulunmuştur. Çeliklere uygulanan IBA dozları arasında en düşük köklenme oranı \%19 ile tanık uygulamasında, en yüksek köklenme oranı ise \% 38 ile 2000 ppm IBA uygulamasından elde edilmiştir. IBA konsantrasyonları arasında köklenme oranına etkileri bakımından değerlendirildiğinde 2000 ppm IBA'nın diğer dozlara göre daha yüksek köklenme sağladığı belirlenmiştir. Anaçlar arasındaki bu farklılık istatistiksel olarak $(\mathrm{p}<0.01)$ düzeyinde çok önemli bulunmuştur. Anaçlar arasında ortalama en yüksek köklenme oranı değeri \%41.3 ile St. Julien anacından, en düşük köklenme oranı değeri \%26.3 ile Garnem anacından elde edilmiştir. Uygulamalar x Anaç interaksiyonundaki farklılık istatistiksel olarak $(\mathrm{p}>0.05)$ düzeyinde önemsiz bulunmuştur. IBA dozu $\mathrm{x}$ anaç interaksiyonu bakımından en yüksek köklenme oranı \%45 olarak 1000 ppm IBA ve
2000 ppm IBA St Julien anacı kombinasyonundan, en düşük köklenme oranı \%10 ile Garnem anacı ve SL-64 anacı tanık uygulamasından elde edilmiştir.

Özkan ve Madakbaş (1995)'ın erik anaçlarında IBA'nın 500 ppm ve 2000 ppm dozu kullanılarak odun çelikleri üzerine yaptıkları çalışmada en yüksek köklenme oranını 2000 ppm IBA uygulamasından elde etmişlerdir. Kankaya ve Özyiğit (1998) elmaya anaç olarak kullanılan M9, MM106 ve MM111, ayva ve armuta anaç olarak kullanılan Quince A, erik, kayısı ve şeftaliye anaç olarak kullanilabilen Pixy, Marianna GF 8-1, Myrobalan B, Common Mussel, Marianna GF 31, Saint Julien 6552 ile kiraz klon anaçlarından GM 61/1 ve GM 79'un odun çeliklerinde yürüttükleri çalışmalarında bütün çeliklerin köklendirilmeleri için kullanılan IBA'nın 2500 ppm dozunun iyi sonuç verdiğini bildirmişlerdir. Ayrıca Ahmed ve ark. (2003)'nın şeftali anaçlarında IBA'nın 2500, 3000 ve 4000 ppm dozları kullanılarak odun çelikleri üzerinde yürüttükleri çalışmalarında en yüksek köklenme oranını GF-655 anacında 2500 ppm IBA dozundan elde etmişlerdir. Çalışmanın bulguları ile uyumlu görülen bu araştırmalardaki farklılıklar doz farkı ve ekolojik koşullar olarak açıklanabilir.

Çizelge 3.2. Farklı dozda IBA ve anaçların köklenme oranına etkisi (\%)

\begin{tabular}{|c|c|c|c|c|c|}
\hline \multirow[t]{2}{*}{ Anaç } & \multicolumn{4}{|c|}{ Uygulama } & \multirow{2}{*}{ Satır Ortalaması } \\
\hline & Tanık & 1000ppm & 2000ppm & 4000ppm & \\
\hline Gf-677 & 25.0 & 40.0 & 40.0 & 30.0 & $33.8 \mathrm{~b}$ \\
\hline Garnem & 10.0 & 32.5 & 35.0 & 27.5 & $26.3 c$ \\
\hline St-Julien & 35.0 & 45.0 & 45.0 & 40.0 & $41.3 \mathrm{a}$ \\
\hline S1-64 & 10.0 & 35.0 & 35.0 & 27.5 & $26.9 c$ \\
\hline Marianna & 15.0 & 35.0 & 35.0 & 27.5 & $28.1 \mathrm{c}$ \\
\hline Sütun Ortalaması & $19.0 \mathrm{c}$ & $37.5 \mathrm{a}$ & $38.0 \mathrm{a}$ & $30.5 b$ & \\
\hline
\end{tabular}

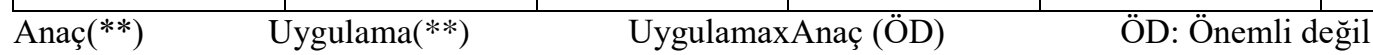

Farklı harfle gösterilen ortalamalar arasındaki fark (**) \%1 ve (*) \%5 düzeyinde önemlidir 


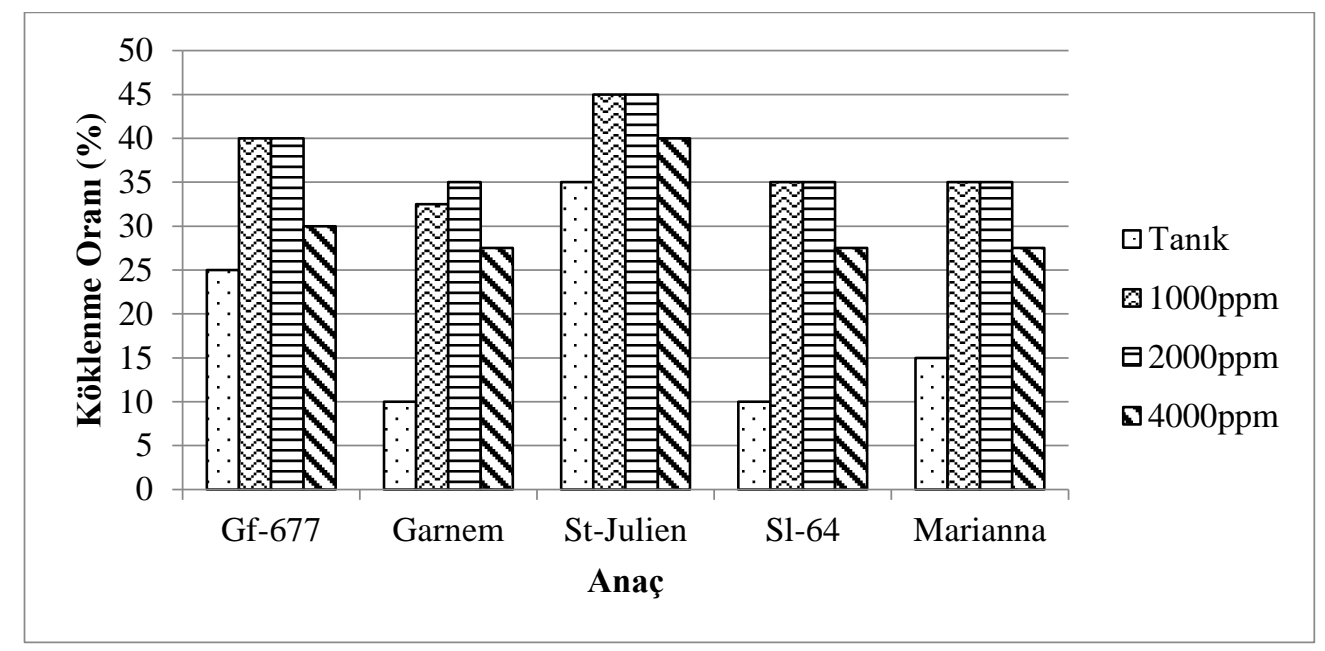

Şekil 3.2. Bazı Prunus türüne ait odun çeliklerine farklı IBA dozlarının köklenme oranı üzerine etkisi

\section{Canlı Çelik Oranı}

GF-677, Garnem, Marianna GF 8-1, St. Julien ve SL-64 klon anaçlarına uygulanan farklı IBA dozlarının canlı çelik oranına olan etkileri Çizelge 3.3 ve Şekil 3.3 'de verilmiştir. Çalışmada Uygulamalar ve Anaç farklılıkları istatistiksel olarak $(\mathrm{p}<0.01)$ düzeyinde çok önemli bulunurken, Uygulamalar x Anaç interaksiyonundaki farklılık istatistiksel olarak $(\mathrm{p}<0.05)$ düzeyinde önemli bulunmuştur. IBA dozları tanık uygulamasına göre daha yüksek bir köklenme oranı göstermiştir. Çeliklerde en düşük canlı çelik oranı $\% 50.5$ ile tanık uygulamasından elde edilirken, en yüksek canlı çelik oranı ise \%88.5 ile 2000 ppm IBA dozundan elde edilmiştir. Canlı çelik oranı anaçlara göre istatistiki açıdan farklılık göstererek en yüksek \%86.3 ile St. Julien anacından, en düşük ise \%63.1 ile Garnem anacından elde edilmiștir. Farklı IBA dozu x anaç interaksiyonu bakımından en yüksek değer $\% 97.5$ ile 2000 ppm IBA Marianna anaç kombinasyonundan elde edilirken, en düşük değer $\% 32.5$ ile Garnem anacının tanık uygulamasından elde edilmiştir. Bu bulgular Reighard ve ark., (1990)'nın erik, şeftali, badem, kayısı'nın 400 genotipi üzerinde IBA'nın 2000 ppm dozunu kullanarak odun çelikleri üzerinde yürüttükleri çalışmanın bulguları ile benzerlik göstermektedir. Ayrıca Sharma ve Aier (1989) erikte odun çeliklerine IBA'nın 0, 2000, 3000 ve 4000 ppm dozlarını kullanarak yürüttükleri çalışmalarında, en yüksek canlı çelik oranına 2000 ppm IBA $(\% 76,4)$ ile elde etmişlerdir. Yapılan çalışmalar ile elde ettiğimiz sonuçlar arasındaki farklılıklar ekolojik koşullar ve bakım koşulları olarak açıklanabilir.

Çizelge 3.3. Farklı dozda IBA ve anaçların canlı çelik oranına etkisi (\%)

\begin{tabular}{|c|c|c|c|c|c|}
\hline \multirow{2}{*}{ Anaç } & \multicolumn{4}{|c|}{ Uygulama } & Satır Ortalamas1 \\
\cline { 2 - 5 } & Tanık & $1000 \mathrm{ppm}$ & $2000 \mathrm{ppm}$ & $4000 \mathrm{ppm}$ & \\
\hline Gf-677 & 62.5 & 90.0 & 91.3 & 78.8 & $80.6 \mathrm{~b}$ \\
\hline Garnem & 32.5 & 75.0 & 77.5 & 67.5 & $63.1 \mathrm{c}$ \\
\hline St-Julien & 70.0 & 95.0 & 92.5 & 87.5 & $86.3 \mathrm{a}$ \\
\hline Sl-64 & 37.5 & 77.5 & 83.8 & 65.0 & $65.9 \mathrm{c}$ \\
\hline Marianna & 50.0 & 92.5 & 97.5 & 75.0 & $78.8 \mathrm{~b}$ \\
\hline Sütun Ortalamas1 & $50.5 \mathrm{c}$ & $86.0 \mathrm{a}$ & $88.5 \mathrm{a}$ & $74.8 \mathrm{~b}$ & \\
\hline
\end{tabular}

Anaç(**) Uygulama(**) UygulamaxAnaç (*)

ÖD: Önemli değil

Farklı harfle gösterilen ortalamalar arasındaki fark (**) \%1 ve $(*) \% 5$ düzeyinde önemlidir 


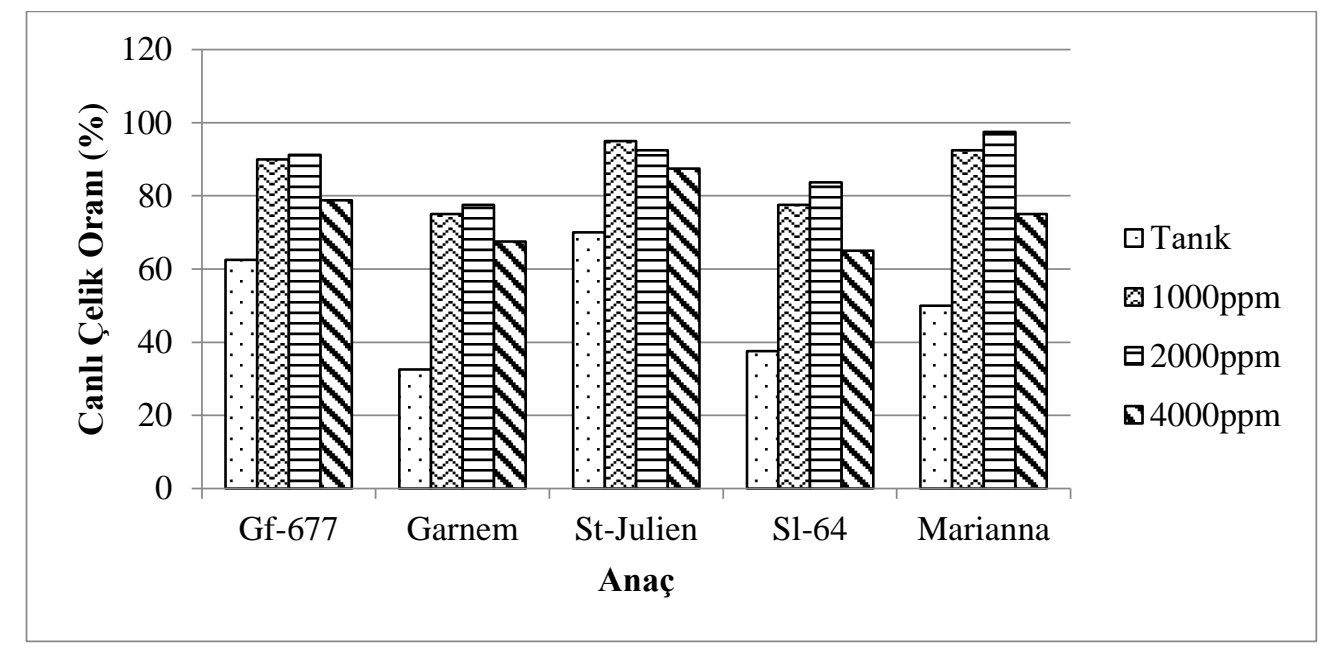

Şekil 3.3. Bazı Prunus türüne ait odun çeliklerine farklı IBA dozlarının canlı çelik oranı üzerine etkisi

\section{Ortalama Kök Sayısı}

GF-677, Garnem, Marianna GF 8-1, St. Julien ve SL-64 klon anaçlarına uygulanan farklı IBA dozlarının ortalama kök sayısına olan etkileri Çizelge 3.4 ve Şekil 3.4'te verilmiştir. Genel olarak farklı IBA dozları uygulanmış çelikler, tanık çeliklere göre, daha olumlu sonuçlar vermişlerdir. Kök sayısı bakımından uygulamalar arasındaki farklılık istatistiksel olarak $(\mathrm{p}<0.01)$ düzeyinde çok önemli bulunmuştur. En yüksek değer 4.5 adet ile 2000 ppm IBA, en düşük değer ise 1.9 ile tanık uygulamasından elde edilmiştir. Ortalama kök sayısı anaçlara göre istatistiki açıdan farklılık $(\mathrm{p}<0.01)$ göstererek en yüksek değer 4.55 adet ile St.Julien anacında, en düşük değer ise 2.9 adet ile SL-64 anacında elde edilmiştir. Çalışmada Uygulamalar $\mathrm{x}$ Anaç interaksiyonundaki farklılık istatistiksel olarak $(\mathrm{p}>0.05)$ düzeyinde önemsiz bulunmuştur. Farklı IBA dozu x anaç interaksiyonu bakımından en yüksek değer 6 adet ile 1000 ppm IBA St.Julien anacı kombinasyonundan elde edilirken, en düşük değer ise 1.1 adet ile SL-64 anacının tanık uygulamasından elde edilmiştir. Mendilcioğlu (1980), can eriğinde yeşil çeliklerde IBA'nın 2500 ppm dozu kullanarak yürüttüğü çalışmasında ortalama kök sayısı bakımından en yüksek 22,75 adet olarak bulduğu bildirmiştir. Ayrıca Küden ve Adıyaman (1993)'de Damas 1869 ve St.Julien A erik anaçlarının odun çeliklerine IBA'nın 0, 1250 ve 2500 ppm dozlarını uygulayarak yaptıkları çalışmada ortalama kök sayısı yönünden 2500 ppm IBA (21,4 adet) dozunun en iyi sonucu verdiğini bildirmiştir. Çalışmalar ile elde ettiğimiz sonuçlar arasındaki farklılıklar ekolojik koşullar ve çeliğin alındığ 1 dönemdeki beslenme durumu olarak açıklanabilir.

Çizelge 3.4. Farklı dozda IBA ve anaçların kök sayısı (adet)

\begin{tabular}{|c|c|c|c|c|c|}
\hline \multirow{2}{*}{ Anaç } & \multicolumn{4}{|c|}{ Uygulama } & \multirow{2}{*}{ Satır Ortalaması } \\
\hline & Tanık & 1000ppm & 2000ppm & 4000ppm & \\
\hline Gf-677 & 1.7 & 4.9 & 4.5 & 3.8 & $3.7 \mathrm{~b}$ \\
\hline Garnem & 1.3 & 3.5 & 4.2 & 2.8 & $2.9 \mathrm{c}$ \\
\hline St-Julien & 3.1 & 6.0 & 5.8 & 3.4 & $4.6 \mathrm{a}$ \\
\hline S1-64 & 1.1 & 3.8 & 3.7 & 2.9 & $2.9 \mathrm{c}$ \\
\hline Marianna & 2.4 & 3.8 & 4.3 & 2.9 & $3.3 \mathrm{bc}$ \\
\hline Sütun Ortalaması & $1.9 \mathrm{c}$ & $4.4 \mathrm{a}$ & $4.5 \mathrm{a}$ & $3.1 \mathrm{~b}$ & \\
\hline
\end{tabular}

$\begin{array}{llll}\text { Anaç(**) Uygulama(**) ÖD } & \text { UygulamaxAnaç (ÖD) Önemli değil }\end{array}$

Farklı harfle gösterilen ortalamalar arasındaki fark $\left({ }^{* *}\right) \% 1$ ve $\left({ }^{*}\right) \% 5$ düzeyinde önemlidir 


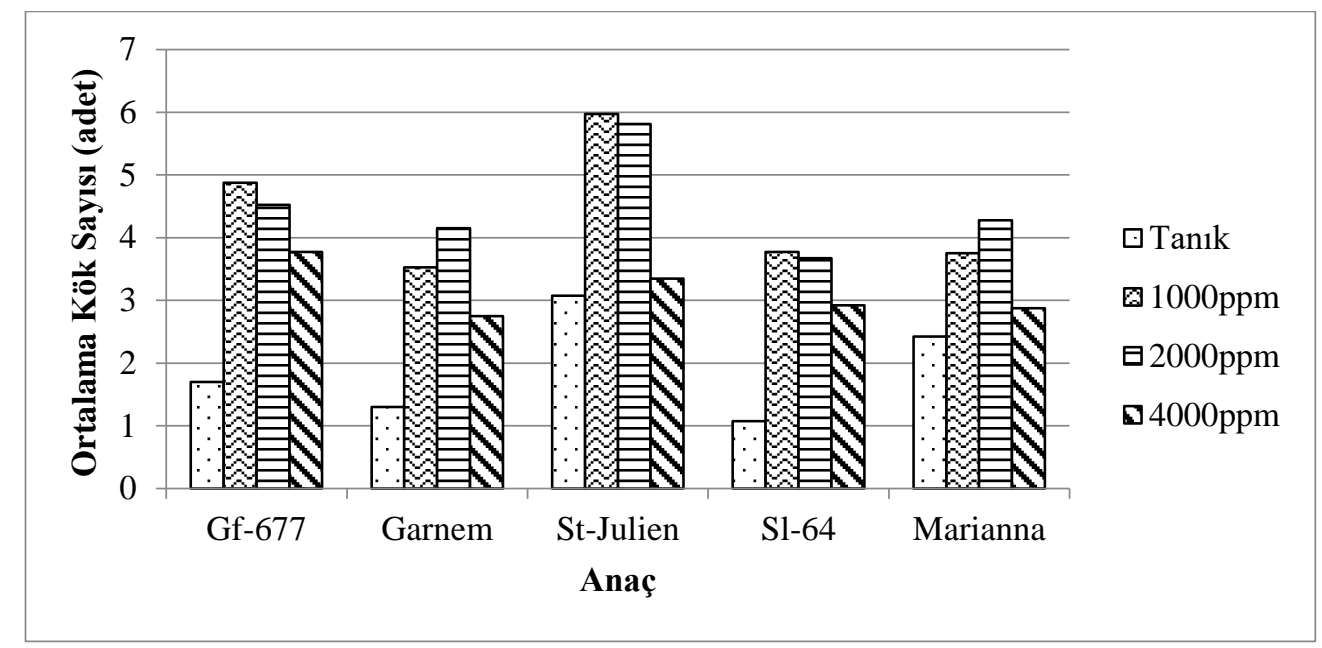

Şekil 3.4. Bazı Prunus türüne ait odun çeliklerine farklı IBA dozlarının ortalama kök sayısı üzerine etkisi

\section{Ortalama Kök Uzunluğu}

GF-677, Garnem, Marianna GF 8-1, St. Julien ve SL-64 klon anaçlarına uygulanan farklı IBA dozlarının ortalama kök uzunluğuna olan etkileri Çizelge 3.5 ve Şekil 3.5 'de verilmiştir. Genel olarak farklı IBA dozları uygulanmış çelikler, tanık çeliklere göre, daha olumlu sonuçlar vermişlerdir. Kök uzunluğu bakımından uygulamalar arasındaki farklılık istatistiksel olarak $(\mathrm{p}<0.01)$ düzeyinde çok önemli bulunmuştur. IBA dozları tanığa göre ortalama kök sayısını artırırken, en yüksek değer $43.7 \mathrm{~mm}$ ile 2000 ppm uygulamasından, en düşük değer ise $15.4 \mathrm{~mm}$ ile tanık uygulamasından elde edilmiştir. Ortalama kök uzunluğu anaçlara göre istatistiki açıdan farklılık $(\mathrm{p}<0.01)$ çok önemli bulunmuştur. En yüksek değer $40.5 \mathrm{~mm}$ ile Marianna anacından, en düşük değer ise $24 \mathrm{~mm}$ ile GF-677 anacından elde edilmiştir. Çalışmada Uygulamalar $\mathrm{x}$ Anaç interaksiyonundaki farkl1lık istatistiksel olarak $(p<0.01)$ düzeyinde çok önemli bulunmuştur. IBA dozu $\mathrm{x}$ anaç interaksiyonu bakımından en yüksek değer 50.5 mm ile 2000 ppm IBA Marianna kombinasyonundan, en düşük değer ise 9.1 mm ile GF-677 anacının tanık uygulamasından elde edilmiştir. Polat ve ark. (1997) can eriklerinde IBA'nın 500, 1000 ve 2000 ppm dozları uygulayarak odun çeliklerinde yaptığı çalışmada en iyi kök uzunluğuna (10.43 adet) IBA'nın 2000 ppm dozundan elde etmişlerdir. Çalışmalar ile elde ettiğimiz sonuçlar arasındaki farklılıklar ekolojik koşullar ve çeliğin alındığı dönemdeki beslenme durumu olarak açıklanabilir.

Çizelge 3.5. Farklı dozda IBA ve anaçların kök uzunluğu (mm)

\begin{tabular}{|c|c|c|c|c|c|}
\hline \multirow{2}{*}{ Anaç } & \multicolumn{4}{|c|}{ Uygulama } & \multirow{2}{*}{$\begin{array}{c}\text { Satır } \\
\text { Ortalamas1 }\end{array}$} \\
\hline & Tanık & 1000ppm & 2000ppm & 4000ppm & \\
\hline Gf-677 & 9.1 & 27.5 & 37.5 & 21.8 & $24.0 \mathrm{c}$ \\
\hline Garnem & 10.9 & 41.5 & 48.2 & 30.7 & $32.8 b$ \\
\hline St-Julien & 15.8 & 37.0 & 41.1 & 26.1 & $30.0 \mathrm{~b}$ \\
\hline S1-64 & 11.3 & 39.9 & 41.2 & 29.3 & $30.4 \mathrm{~b}$ \\
\hline Marianna & 30.0 & 48.5 & 50.5 & 33.0 & $40.5 a$ \\
\hline $\begin{array}{c}\text { Sütun } \\
\text { Ortalamas1 }\end{array}$ & $15.4 \mathrm{~d}$ & $38.9 b$ & $43.7 \mathrm{a}$ & $28.1 \mathrm{c}$ & \\
\hline
\end{tabular}

\begin{tabular}{llll}
\hline Anaç $(* *)$ & Uygulama $(* *)$ & ÖD: Önemli değil
\end{tabular}

Farklı harfle gösterilen ortalamalar arasındaki fark (**) \%1 ve (*) \%5 düzeyinde önemlidir 


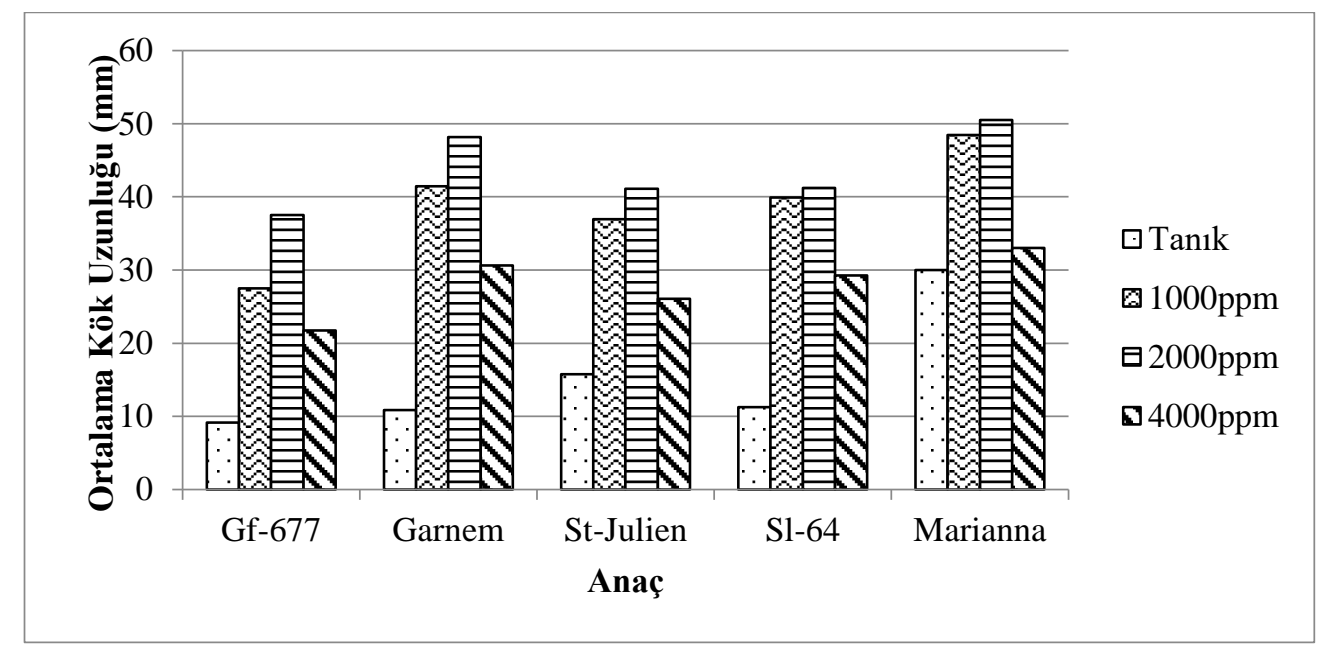

Şekil 3.5. Bazı Prunus türüne ait odun çeliklerine farklı IBA dozlarının ortalama kök uzunluğu üzerine etkisi

\section{SONUC}

Prunus türüne ait bazı meyve klon anaçlarından şeftali (GF-677, Garnem), erik (Marianna GF 8-1, St. Julien) ve kiraz (SL-64) anaçlarının odun çeliklerine uygulanan IBA'nın 0, 1000, 2000 ve 4000 ppm dozlarının incelenen köklenme oranı (\%), kallus oluşum oranı $(\%)$, canlı çelik oranı $(\%)$, ortalama kök sayısı (adet) ve ortalama kök uzunluğu (mm) gibi özellikler üzerine önemli derecede olumlu etkisi olmuştur. Elde edilen verilere göre; en yüksek köklenme oranı \%38 ile 2000 ppm IBA dozundan elde edilmiştir. Çalışmamızda kullandığımız anaçların odun çeliklerinde incelenen özellikler için en uygun IBA dozunun 2000 ppm olduğu belirlenmiştir. Daha sonraki yapılacak araştırmalara 1 şı tutması açısından önemli olan çalışmamızda, daha iyi değerler elde etmek isteyen araştırıcılar; çelik alma zamanı, hormon dozları ve çelik alınacak ağacın beslenme özellikleri gibi kriterlere dikkat edilmesi tavsiye edilebilir.

\section{KAYNAKLAR}

Ağaoğlu YS, Çelik H, Çelik M, Fidan Y, Gülşen Y, Günay A, Halloran N, Köksal Aİ, Yanmaz R 2001. Genel Bahçe Bitkileri. Ankara Üniversitesi Eğitim Araştırma ve Geliştirme Vakfı Yayınları Yayın No: 4, Ankara. $350 \mathrm{~s}$.

Ahmed MS, Abbasi NA, Amer M 2003. Effects of IBA on Hardwood Cuttings of Peach Rootstocks Under Greenhouse Conditions. Asian Journal of Plant Sciences 2(3): 265-269

Barut E 2008. Meyvecilik Tekniği. (Genel Meyvecilik Kitabı-Meyve Yetiştiriciliğinin Esasları Ed. Gerçekçioğlu R, Bilginer Ş, Soylu A). Nobel Basımevi. 107-153

Edizer Y, Demirel MA 2012. Bazı Klon Meyve Türlerinde Klon Anaçlarının Yeşil Çeliklerinin Sisleme Ünitesinde Köklendirilmeleri Üzerine Bir Çalışma. Gaziosmanpaşa Üniversitesi Ziraat Fakültesi Dergisi, 29 (2), 1-8
Ilgın M, Bulat L 2014. GF-677 Klon Anacında Çelik Alma Zamanı ile Farklı Dozlardaki IBA (Indol-3 Bütirik Asit) Uygulamalarının Köklenme Başarısına Etkileri. Alatarım 13 (2): 15-22

Kankaya A, Özyiğit S 1998. Bazı Klon Anaçlarının Çelikle Çoğaltılabilirliği. I. Ege Bölgesi Tarım Kongresi. 7-11 Eylül 1998. Aydın.

Kaşka N, Yılmaz M 1974. Bahçe Bitkileri Yetiştirme Tekniği. Çukurova Üniversitesi Ziraat Fakültesi Yayın no:79, $601 \mathrm{~s}$

Küden A, Adıyaman A 1993. Damas 1869 ve St. Julien A Erik Anaç Çeşitlerinin Farklı Ortamlarda Köklendirilmesi. Çukurova Üniversitesi Ziraat Fakültesi Dergisi, 8(2):160-165

Mendilcioğlu K 1980. Bazı Can Eriklerinin Odunsu Çelikler İle Çoğlatılması Üzerine Araştırmalar. Ege Üniversitesi Ziraat Fakültesi Dergisi, 17(3):85-98

Özkan Y, Madakbaş SY 1995. Bazı Erik Klon Anaçlarının Odun Çelikleriyle Üretilmesi Üzerinde Araştırmalar. Gaziosmanpaşa Üniversitesi Ziraat Fakültesi Dergisi 12, 1-7

Polat AA, Kamiloğlu Ö, Durgaç C 1997. Açık Arazide Can Erikleri Odun Çeliklerinin Köklendirilmesi Üzerine Indol Butirik Asidin (IBA) Etkisi. Mustafa Kemal Üniversitesi Ziraat Fakültesi Dergisi 2(2)103114

Reighard GL, Cain DW, Newall WC 1990. Rooting and Survival Potential of Hardwood Cuttings of 406 Species, Cultivars and Hybrids of Prunus. Hortscience 25(5):517-518.

Sharma SD, Aier NB, 1989. Seasonal Rooting Behaviour of Cuttings of Plum Cultivars as Influenced by IBA Treatments. Scientia Horticulturae, 40 (297-303)

Şen SM, Balta F 1990. Bazı Önemli Şeftali Çeşitlerinin Sert Odun Çelikleriyle Çoğaltılması Üzerine Bir Araştırma. Yüzüncü Y1l Üniversitesi Ziraat Fakültesi Dergisi 1 (1): 129-136 